\title{
A post-Tohoku earthquake review of earthquake probabilities in the Southern Kanto District, Japan
}

\author{
Paul G Somerville
}

\begin{abstract}
The 2011 Mw 9.0 Tohoku earthquake generated an aftershock sequence that affected a large part of northern Honshu, and has given rise to widely divergent forecasts of changes in earthquake occurrence probabilities in northern Honshu. The objective of this review is to assess these forecasts as they relate to potential changes in the occurrence probabilities of damaging earthquakes in the Kanto Region. It is generally agreed that the $2011 \mathrm{Mw} 9.0$ Tohoku earthquake increased the stress on faults in the southern Kanto district. Toda and Stein (Geophys Res Lett 686, 40: doi:10.1002, 2013) further conclude that the probability of earthquakes in the Kanto Corridor has increased by a factor of 2.5 for the time period 11 March 2013 to 10 March 2018 in the Kanto Corridor. Estimates of earthquake probabilities in a wider region of the Southern Kanto District by Nanjo et al. (Geophys J Int, doi:10.1093, 2013) indicate that any increase in the probability of earthquakes is insignificant in this larger region. Uchida et al. (Earth Planet Sci Lett 374: 81-91, 2013) conclude that the Philippine Sea plate the extends well north of the northern margin of Tokyo Bay, inconsistent with the Kanto Fragment hypothesis of Toda et al. (Nat Geosci, 1:1-6,2008), which attributes deep earthquakes in this region, which they term the Kanto Corridor, to a broken fragment of the Pacific plate. The results of Uchida and Matsuzawa (J Geophys Res 115:B07309, 2013)support the conclusion that fault creep in southern Kanto may be slowly relaxing the stress increase caused by the Tohoku earthquake without causing more large earthquakes. Stress transfer calculations indicate a large stress transfer to the Off Boso Segment as a result of the 2011 Tohoku earthquake. However, Ozawa et al. (J Geophys Res 117:B07404, 2012) used onshore GPS measurements to infer large post-Tohoku creep on the plate interface in the Off-Boso region, and Uchida and Matsuzawa (ibid.) measured similar large creep off the Boso Peninsula. Thus some of the large stress transfer may be undergoing aseismic release, consistent with pre-Tohoku geodetic data, so a large earthquake on the Off Boso segment may have a low probability.
\end{abstract}

\section{Introduction}

The $2011 \mathrm{Mw} 9.0$ Tohoku earthquake generated an earthquake sequence that affected a large part of northern Honshu, including plate boundary regions of the Okhotsk, Pacific, Philippine Sea and Eurasian plates (e.g. [1]). It is generally agreed that the $2011 \mathrm{Mw} 9.0$ Tohoku earthquake has increased the stress on faults in the southern Kanto district through the mechanism of stress transfer. However, there currently exist widely divergent forecasts of changes in earthquake occurrence probabilities in the southern Kanto district. There are also widely divergent models of the configuration of subducted plates beneath the southern Kanto District. The objective of this review is to assess these divergent forecasts and models in

Correspondence: paul.somerville@mq.edu.au

Risk Frontiers, Room 817, Building E7A, Macquarie University, North Ryde, NSW 2109, Australia order to provide an improved basis for understanding potential changes in the occurrence probabilities of damaging earthquakes in the Kanto Region due to the occurrence of the 2011 Tohoku earthquake. Earthquake magnitudes cited in this review are either moment magnitude (Mw) or JMA magnitude (Mjma).

\section{Review}

The 2011 Tohoku earthquake and plate boundary interactions

The plate boundaries in central Japan and the location of the 11 March $2011 \mathrm{Mw} 9.0$ Tohoku earthquake are shown in Figure 1. Intense interest is now focused on the evolution of the earthquake sequence that began with this earthquake. It generated seismic activity over a vast area of Japan (Figure 2), which is a manifestation of the widespread changes in the stress field that it generated. In addition to the five earthquakes in the Mjma magnitude

\section{实}




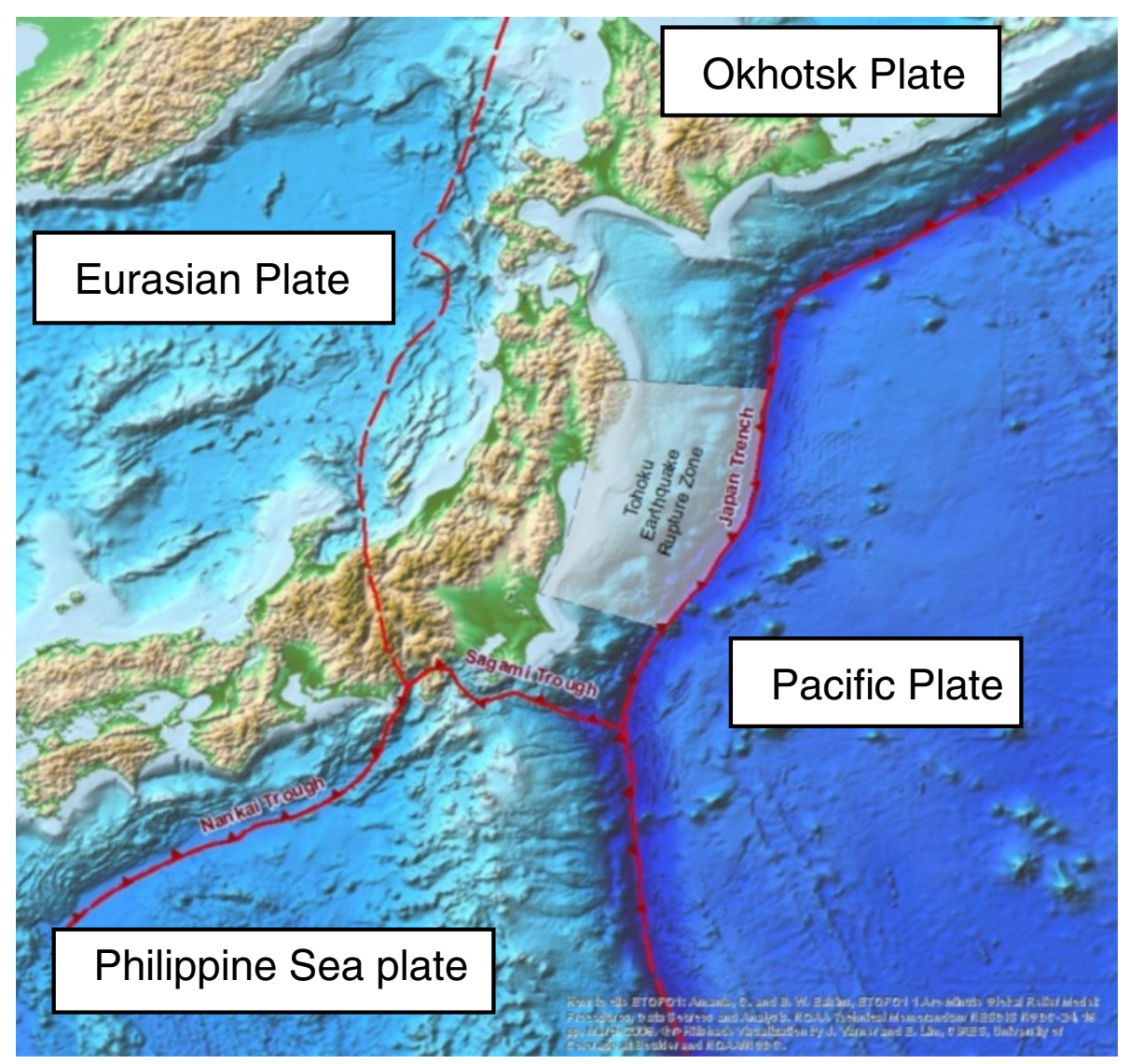

Figure 1 Plate boundaries in central Japan.

range of 7.2 to 7.7 that occurred offshore within the rupture zone of the mainshock, the Tohoku earthquake generated aftershocks as large as Mjma magnitude 6.7 further afield throughout central and northern Honshu. The three red-circled aftershocks that run from north to south on the left side of Figure 2 all occurred close to the boundary (shown by the thin blue line) between the Okhotsk plate (on which northern Japan is situated) and the Eurasian plate (on which western Japan is situated). This suggests that the Tohoku earthquake, which occurred on the interface between the Pacific plate and the Okhotsk plate, may be causing interactions between the Okhotsk and Eurasian plates, indicating the potential for further aftershocks occurring over an extended region of Japan. The main focus of this paper is on the influence of the Tohoku earthquake on earthquake probabilities in the southern Kanto District, within which Tokyo is located.

\section{Historical earthquakes affecting Tokyo}

Historical earthquakes that have affected Tokyo are shown in Figure 3. The fault planes of the larger earthquakes are shown as rectangles indicating their year of occurrence, and the smaller earthquakes are shown as open circles. Although Tokyo is subject to earthquakes occurring on many different sources, two categories of sources are most prominent. The first is the interface between the Philippine Sea plate and the Okhotsk plate, which underlies the southern part of Tokyo. The 1923 Mw 8 Kanto earthquake (e.g. [2]) caused widespread destruction in Tokyo. The previous earthquake on this plate interface is thought to have occurred in 1703 and to have ruptured on a fault extending further to the east-southeast. The 2011 Tohoku earthquake is thought to have reduced the stress on the region of the plate interface that ruptured in 1923, as described further below, and so this region of the plate interface is not currently a focus of major concern regarding future earthquakes in Tokyo.

The second category of earthquake sources consists of smaller, deeper earthquakes occurring within the subducting Pacific and Philippine Sea plates beneath southern Kanto, and on the interface between these plates (e.g. [6]). Historically these earthquakes have had estimated magnitudes up to $\mathrm{Mw} 7.3$ and have occurred in the depth range of about 40 to $60 \mathrm{~km}$, and so their ground motions in Tokyo are not as strong as those of the larger, shallower 1923 Kanto earthquake. These earthquakes include many of the open circles shown in Figure 3, and may include the Mjma 7.3 Ansei Edo earthquake shown as "1855?" A 


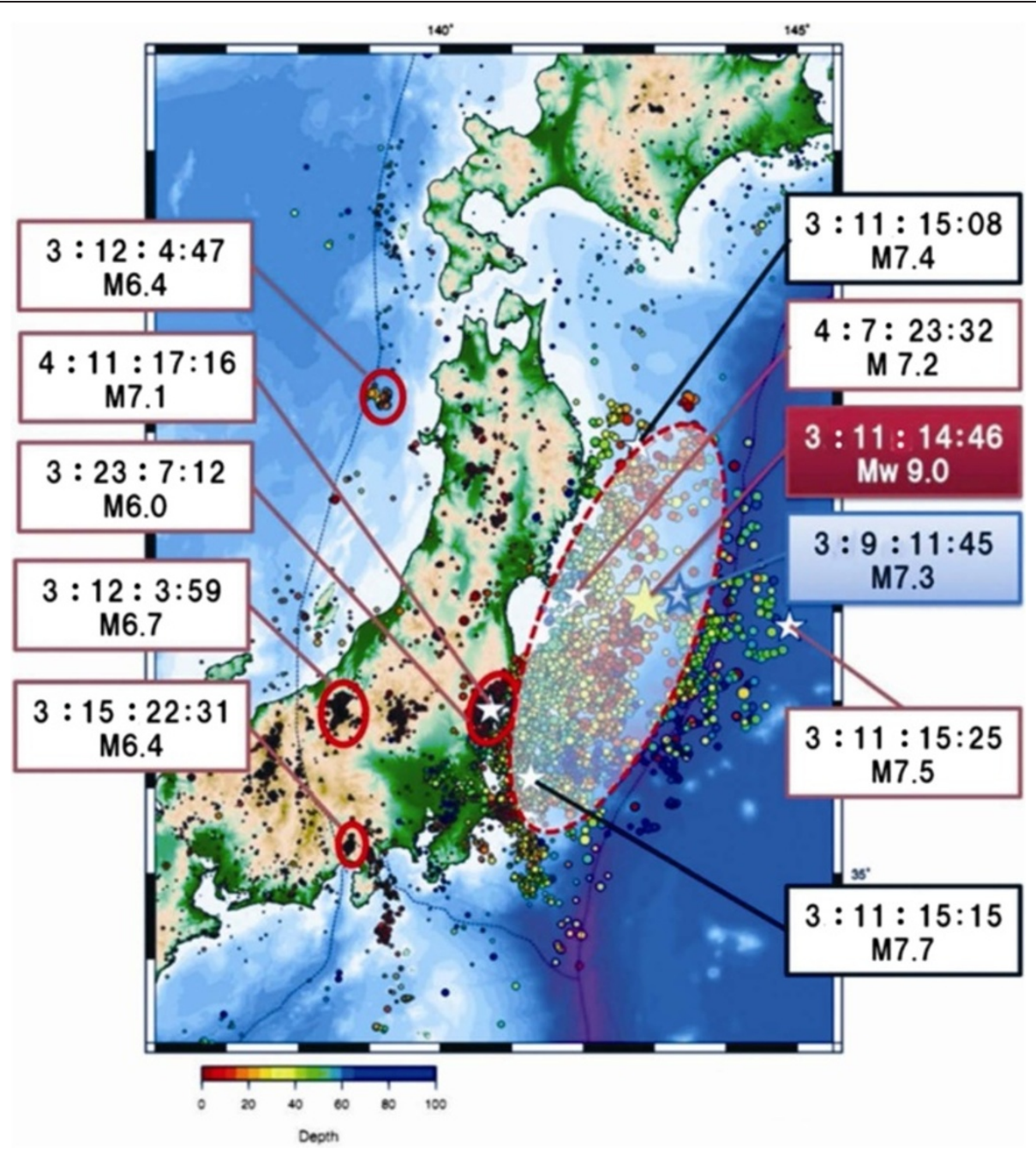

Figure 2 Map of mainshock rupture zone (ellipse) and aftershocks of the 2011 Tohoku earthquake to 8 April 2011 (with JMA event times and magnitudes) and plate boundaries shown by thin blue lines. Source: Oki, Tsuji and Nishida, http://outreach.eri.u-tokyo.ac.jp/ eqvolc/201103_tohoku/eng/aftershocksofpast/.

controversy has recently developed concerning the tectonic association of some of these earthquakes, related to the Kanto Fragment described below in relation to Figure 4.

It is unclear whether a third earthquake source, the Off Boso segment of the interface between the Pacific and Okhotsk plates, has generated large earthquakes in historical time. It is not known whether the November 4, 1677 earthquake off the coast of the Boso Peninsula (Figure 3), with estimated magnitude $\mathrm{Mw} 8$, was an earthquake on the plate interface or one occurring within the subducting plate. That earthquake was accompanied by a tsunami that extended from Fukushima Prefecture to the Boso Peninsula coast, where more than 246 people drowned. It has been suggested that this could have been a "tsunami earthquake" ("slow earthquake" or "low-frequency earthquake") with fault slip occurring more slowly than that of typical earthquakes. The Off Boso segment is located immediately south of the 2011 Tohoku earthquake rupture zone, giving rise to concern that the occurrence of the Tohoku earthquake could trigger a large earthquake on the adjacent Off Boso segment of the plate interface. Such an earthquake has the potential to be more damaging to Tokyo than was the 2011 Tohoku earthquake, although Sekiguchi et al. [8] concluded that such Off Boso earthquake scenarios do not yield high ground motion intensities on land. We use available interpretations to assess the extent to which this part of the plate interface is creeping (slipping without generating quakes), or is locked and building strain that could be released in a future large earthquake.

To assess the current state of stress in eastern Japan, especially in the Tokyo region, we need to know the state of stress before the earthquake, and understand the 


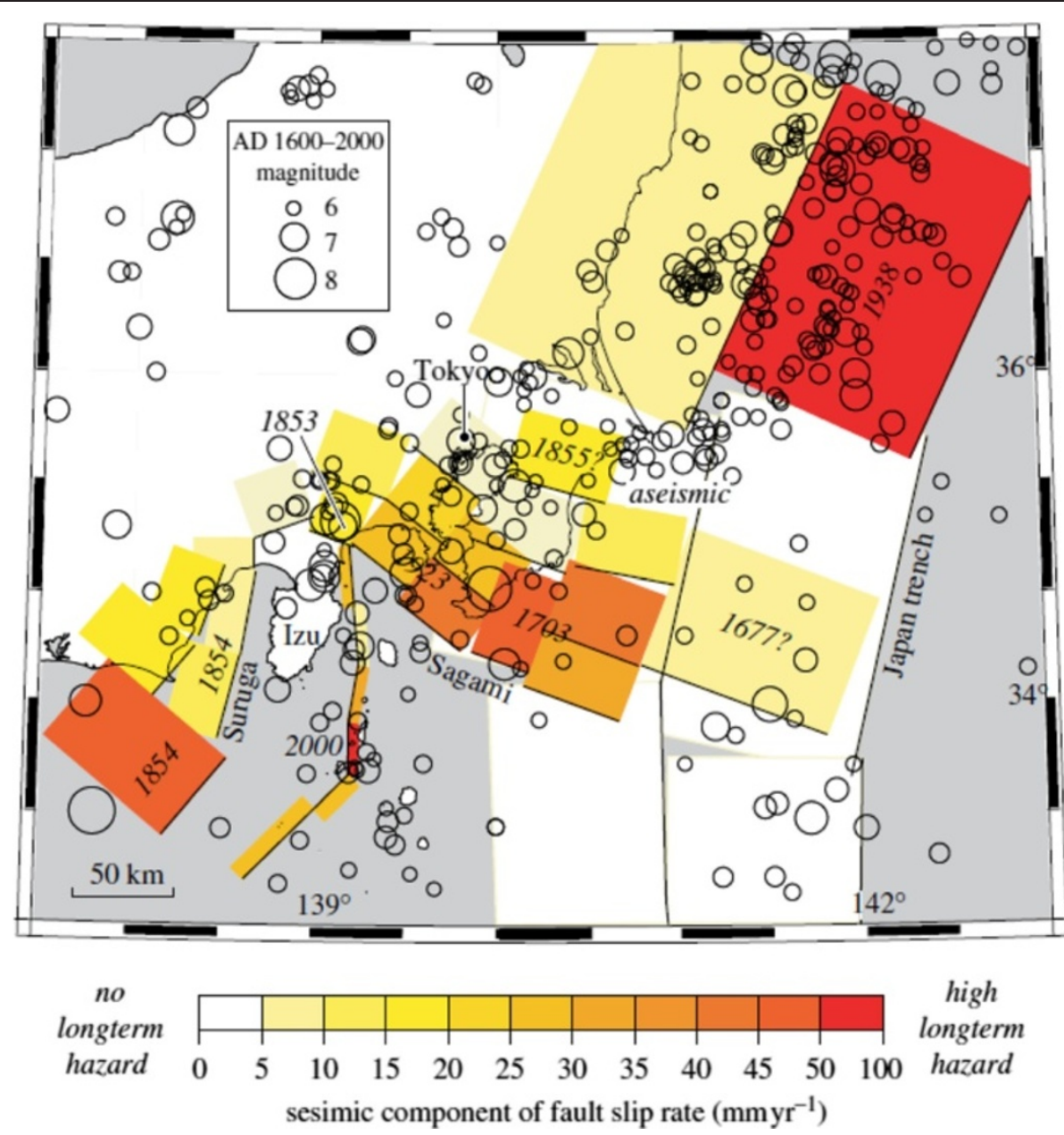

Figure 3 Inferred seismic slip rate for major faults, and their association with larger historical events and historical seismicity as of 2006. Red sources slip at a high rate and are presently locked, and thus are accumulating tectonic strain to be released in future large earthquakes; white sources have low seismic slip rates, so most of their slip occurs as creep and they are unlikely to be sites of future large earthquakes. The red zone marked 1938 is thought to have since ruptured in the Tohoku earthquake. Source: Stein et al. [3]; modified from Nishimura et al. [4].

changes in the stress field that the Tohoku earthquake produced. This depends on how much stress had accumulated along the subduction zone before the earthquake, how much stress was released during the earthquake, and whether stress has been transferred to other faults. To assess whether other faults have been brought closer to rupture in the new stress field, we need to know their locations and orientations and when they last ruptured. We would then like to know how to convert the current stress field into probabilities of earthquakes having specified magnitudes occurring on these faults within a specified time interval. These are very challenging demands on our current understanding of how earthquakes are generated and on our abilities to forecast earthquakes.

To better understand the earthquake hazards in the Tokyo region and the changes in them that the Tohoku earthquake may have caused, we first describe the geometry of subducting plates beneath Tokyo. We next describe some important features of earthquake behavior, including stick-slip (which produces earthquakes) and creep (in which slip occurs on faults without producing earthquakes). We next explore mechanisms of stress transfer that may explain how the Tohoku earthquake could trigger earthquakes on other faults in the region. We then proceed to describe changes in earthquake rates in the Tokyo region following the Tohoku earthquake, and assess the implications of the Tohoku earthquake for a future earthquake on the Off Boso segment.

\section{Geometry of subducting plates beneath Tokyo and the Kanto fragment}

Tokyo is located above the complex intersection of two subducting plates: the Pacific plate which is subducting beneath the Okhotsk plate from the east, and the Philippine Sea plate, which is subducting beneath the 


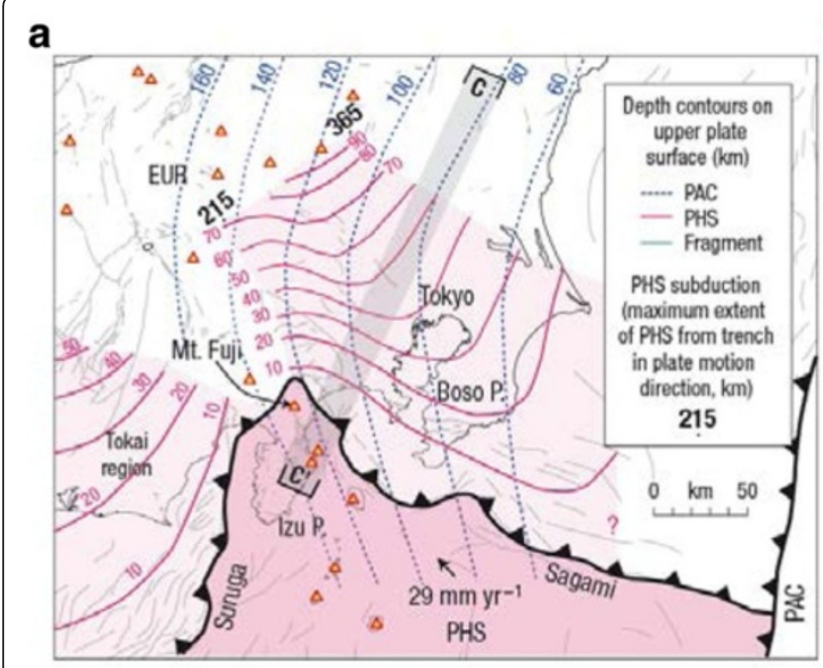

b

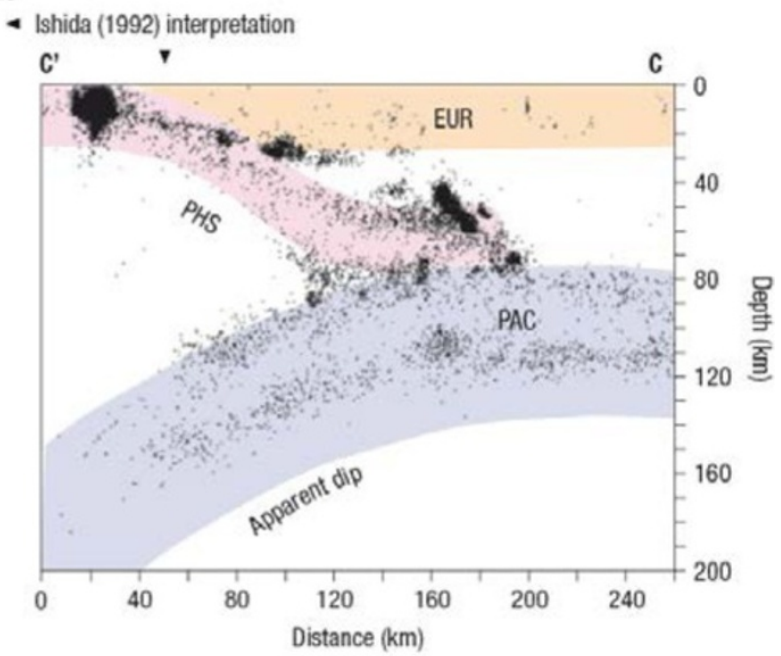

C

d
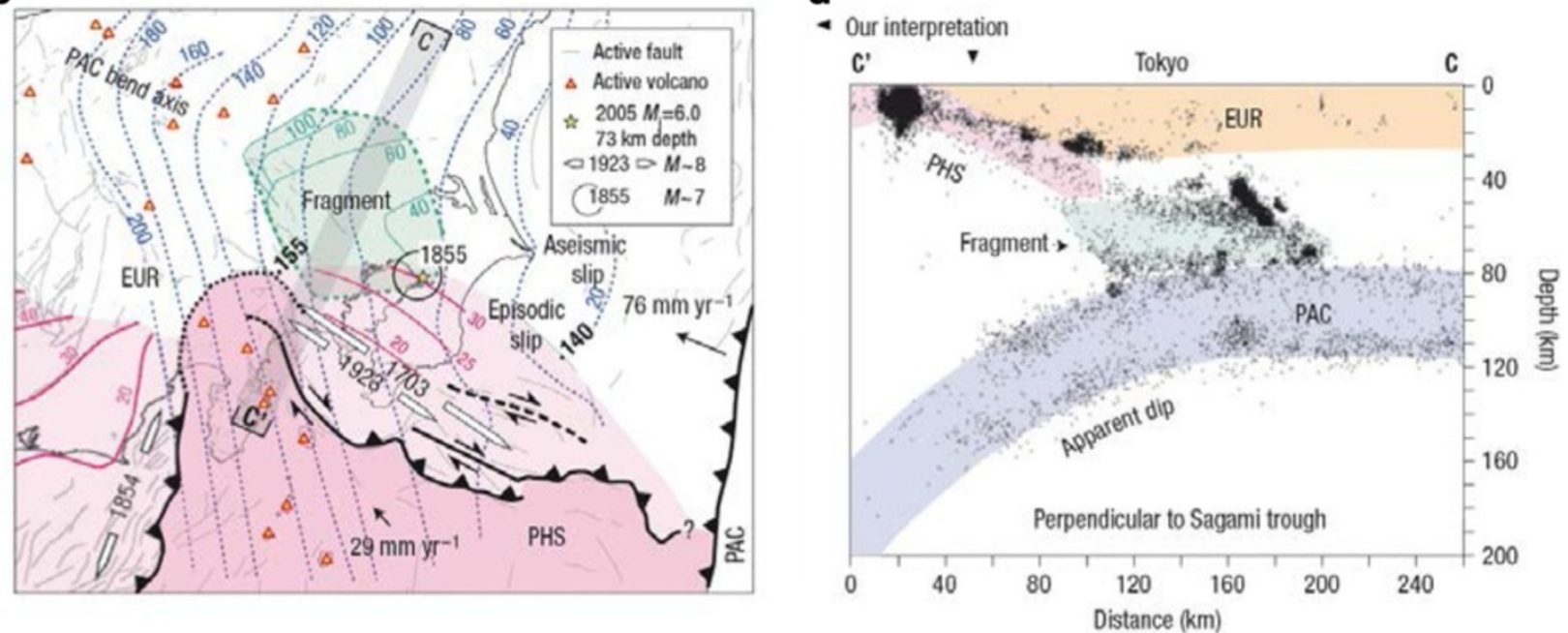

Figure 4 Maps and cross sections in the Kanto region showing the commonly accepted geometry in map view and cross section (a and b) and the Kanto Fragment hypothesis of Toda et al. [7] (c and d). PHS: Philippine Sea plate; PAC: Pacific plate; EUR: Okhotsk plate. Source: Toda et al. [7].

Okhotsk plate from the southeast, as shown in map view and cross section in Figure 4. This figure shows two alternative interpretations of the slab geometry beneath Tokyo. The prevailing view among Japanese seismologists holds that all of the seismicity beneath Tokyo is attributable to the Philippine Sea plate having become warped and folded against the Pacific plate [9-11], shown at the top of Figure 4. In the contrary view of Toda et al. [7], shown at the bottom of Figure 4, many of the earthquakes beneath Tokyo are attributed to a fragment of the Pacific plate that has broken off and become lodged between the Pacific, Philippine Sea and Okhotsk plates (bottom of Figure 4). They suggest that the fragment controls much of Tokyo's seismic behavior, with the concentration of M 7 earthquakes beneath Tokyo attributable to the sliding of the fragment against the three other plates. Unlike previous interpretations, in which the Philippine Sea plate was thought to extend $100 \mathrm{~km}$ north of Tokyo and reach a depth of $90 \mathrm{~km}([9,12])$, they propose that the Philippine Sea slab extends to a depth of only $35 \mathrm{~km}$. If so, the leading edge of the Philippine Sea slab, and thus the northward limit of subduction earthquakes like the 1923 Kanto earthquake, extends only as far north as Tokyo (bottom of Figure 4). Uchida et al. [11] analysed both repeating earthquakes and converted wave data to constrain the geometry of the subducted plates beneath Tokyo. Compared with Toda et al. [7], who proposed the existence of a fragment of the Pacific Plate (PAC) above the PAC north of approximately $35.7^{\circ} \mathrm{N}$, they did not observe any abrupt changes in the thickness of the PHS or depth of the upper boundary of the Philippine Sea Plate (PHS) 
across Latitude $\sim 35.7^{\circ} \mathrm{N}$. They conclude that coincidence of the northeastern limit of the PHS estimated from focal mechanisms with the edge of the wedge shape of the PHS derived from converted wave data supports the validity of their model.

\section{Fault behaviour: stick-slip and creep}

Before investigating the impact of the 2011 Tohoku earthquake on the seismic potential of the Tokyo region, we review some aspects of fault behavior. Earthquakes occur by the sudden movement (seismic slip) across the two sides of a fault. On some faults, there is no sliding between earthquakes; instead the fault is locked. In this case the fault has two states: sudden slip during earthquakes, and complete locking between them, in a process called stick-slip, and such faults are described as strongly coupled. However, on other faults, which we describe as weakly coupled, there may be gradual sliding of the two sides of the fault past each other (aseismic slip or creep), which takes up some of the slip that would otherwise occur suddenly in earthquakes. Such faults have both stick-slip and creeping behavior, and we shall see in Figure 5 below that such behavior occurs in the subduction zones beneath Tokyo and off the Tohoku region of northern Japan. In some locations, faults may release all of their stress aseismically in creep and produce no earthquakes at all even though there is slip across them.

Repeating small earthquakes on the plate interface are thought to occur at small asperities (strong patches) on the fault zone that catch up with aseismic fault slip (creep) on the surrounding surface. This stick-slip behavior in small earthquakes is observed on the subduction plate interface of northeastern Japan, and was used by Uchida and Matsuzawa [14] to estimate the amount of creep at depth.

The location and amount of horizontal deformation of the earth's surface observed by GPS and geodetic levelling data enabled Nishimura et al. [4] to estimate the strain accumulation rate on the major faults, and thus to infer their seismic slip rates, as shown in Figure 3. They found that along the Suruga and Sagami troughs, south of Tokyo, faults are locked and are thus accumulating strain to be released in future earthquakes, indicated by the orange rectangles in Figure 3. In contrast, they concluded that the plate boundary faults east and north of Tokyo partially creep and so produce earthquakes less frequently, although GPS data in the far offshore region are needed to confirm this conclusion. Along the Japan Trench to the northeast of Tokyo, they concluded that the Pacific-Okhotsk plate interface is creeping and thus apparently has a low seismic potential, except the site of the $1938 \mathrm{Mjma} 7.3$, 7.4 and 7.5 earthquake swarm, which they concluded at the time was locked but which is thought to have since ruptured in the 2011 Tohoku earthquake. The creeping zone includes the white and yellow areas east of the Boso Peninsula in Figure 3, which lies east of Tokyo.

The Off Boso segment of the Japan Trench is of particular interest given its proximity to Tokyo and its as yet unproven potential to generate earthquakes larger than magnitude 8. The Earthquake Research Committee [15] earthquake source model does not include an Off Boso earthquake source, in part because no such event has been conclusively identified in the historical record (the 1677 earthquake shown in Figure 3 notwithstanding). It has been thought by many researchers that, instead of accumulating tectonic strain, the Off Boso segment is creeping in an aseismic manner and may be incapable of generating large earthquakes, although the Tohoku earthquake generated several Mjma > 6 aftershocks that may have occurred on this interface. As noted above, the creeping zone in Figure 3 includes the white and yellow areas east of the Boso Peninsula, supporting the prevailing view that it is incapable of generating large earthquakes.

The occurrence of the 2011 Tohoku earthquake was a surprise to many seismologists, because they thought, based on the historical record, that this subduction zone did not have the potential to generate such large earthquakes, and that magnitudes of large earthquakes there would be limited to Mjma 8.4 [15]. The occurrence of the 2011 Tohoku earthquake has raised concern about the seismic potential of the neighboring Off Boso segment. Before exploring that subject, we first need to review the concept of stress transfer.

\section{Stress transfer}

Aftershocks following the occurrence of a mainshock are triggered by two main processes: dynamic triggering and static triggering. Dynamic triggering occurs when seismic waves travelling away from the first earthquake cause transient stress perturbations that trigger aftershocks. This has been observed to occur at quite large distances, but at large distances the triggering appears to be limited to fairly small aftershocks. Static triggering, also known as Coulomb stress transfer (CST), is based on the hypothesis that instantaneous and permanent stress changes near the source region of one earthquake can trigger other earthquakes by increasing the stress on the neighboring faults on which they occur [16].

\section{Stress transfer onto adjacent fault segments}

On plate boundaries, sequences of large earthquakes are often found to progressively rupture the plate interface, with one large earthquake occurring adjacent to and soon after the preceding event. This leads us to inquire whether the occurrence of the 2011 Tohoku earthquake may have increased the likelihood of a large earthquake on the adjacent Off Boso segment to the south. The Nankai Trough in southwestern Japan provides an example of stress transfer (e.g. [17]), as shown in Figure 6. Earthquakes on the 


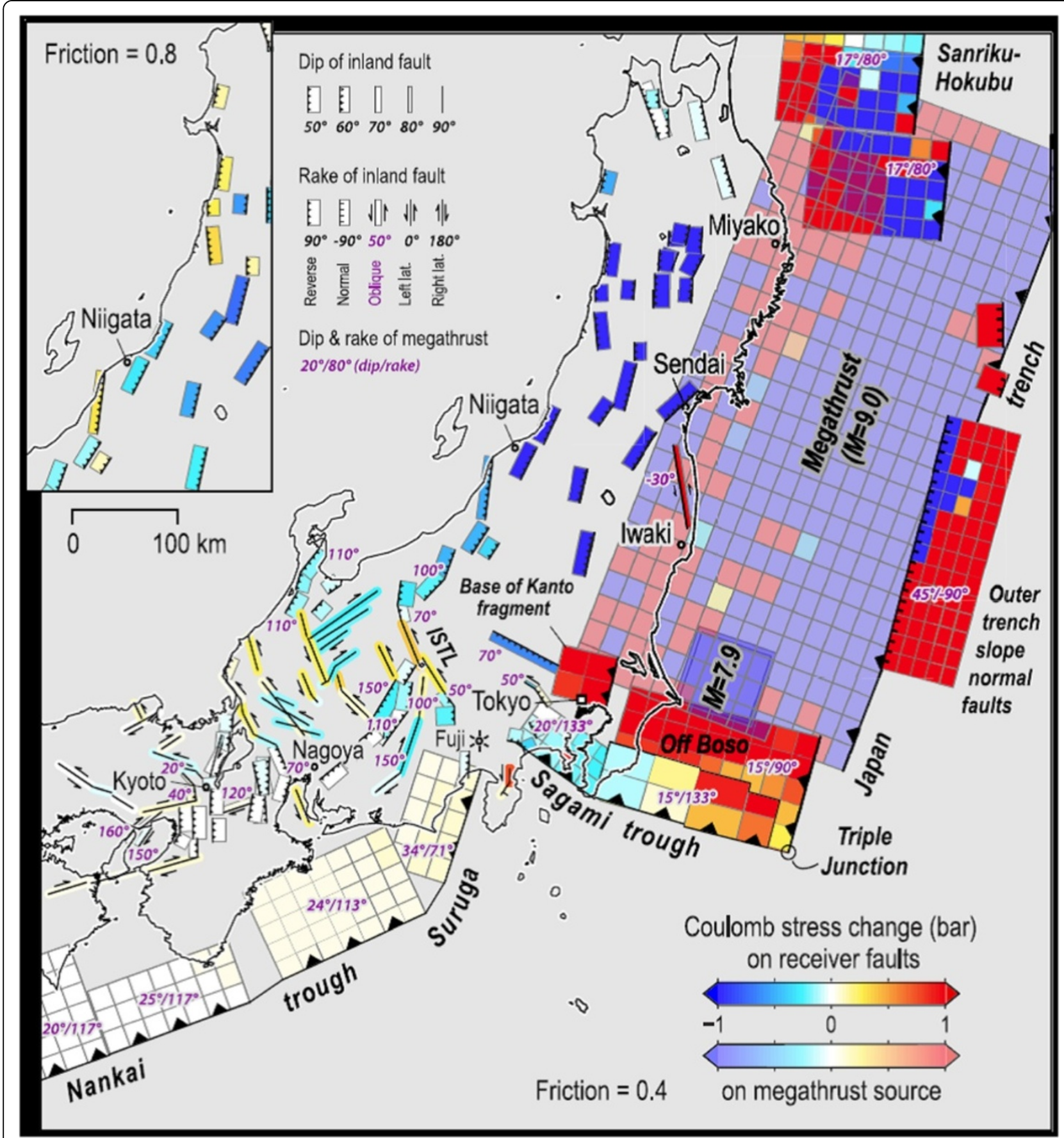

Figure 5 Stress changes imparted by the M9.0 mainshock and M7.9 aftershock to surrounding active faults including the hypothesized Kanto fragment [13]. ISTL is the Itoigawa-Shizuoka tectonic line, thought to form part of the boundary between the Okhotsk plate to the east and the Eurasian plate to the west.

Nankaido, Tonankai and Tokai segments of the Nankai Trough plate interface tend occur at almost the same time, suggesting that one event triggers an event on the adjacent segment. Rupture of the Tonankai segment preceded that of the Nankai segment in the last two sequences: the delay times were 32 hours for the 1854 Ansei events and two years for the 1944 Tonankai and 1946 Nankai events.
Coulomb stress transfer (CST)

The transfer of stress from one fault segment to the neighboring segment on the same fault, described in the above examples, is a special case of the more general phenomenon of stress transfer, which can potentially occur between any pair of separate faults. When an earthquake occurs, it causes instantaneous permanent stress changes 


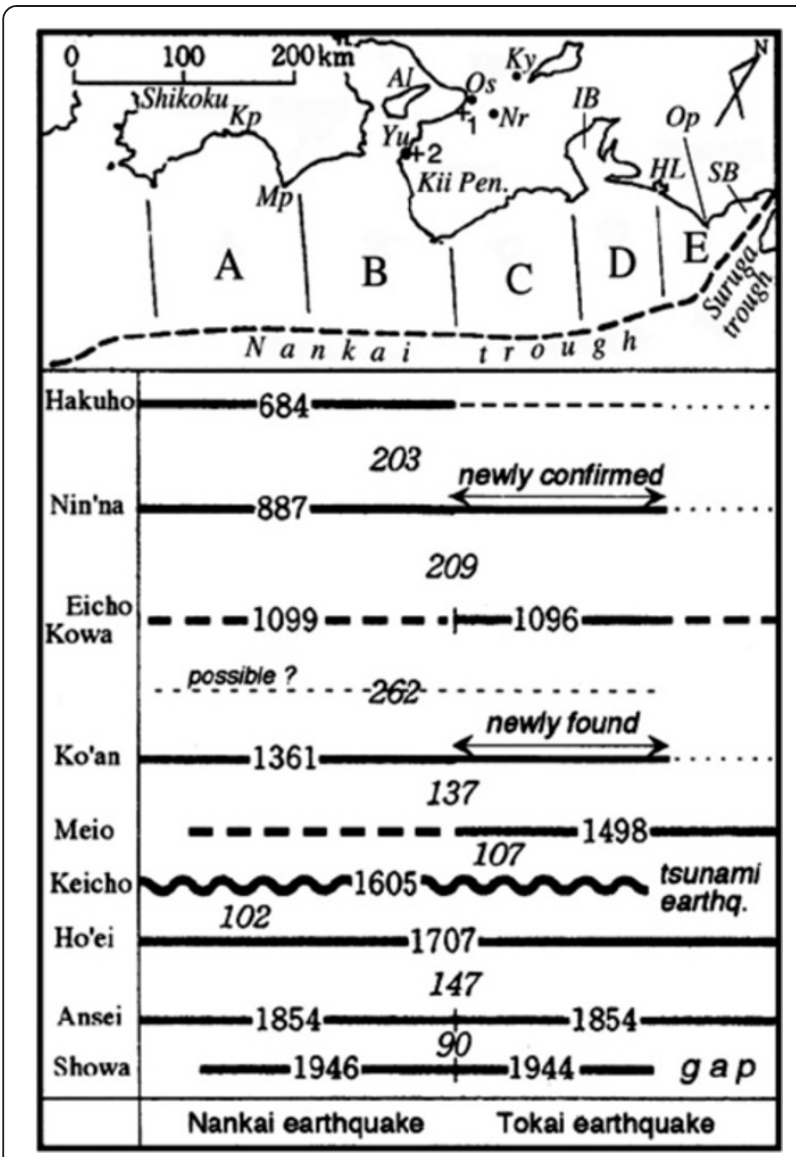

Figure 6 Space-time distribution of great interplate earthquakes along the Suruga-Nankai trough. Roman and italic numerals indicate earthquake occurrence years and time intervals between two successive series, respectively. Thick solid, thick broken, and thin broken lines represent certain, probable, and possible rupture zones, respectively. Thin dotted lines indicate unknown. A to $E$ are commonly used subdivisions of rupture zones. Source: Ishibashi [5].

throughout the surrounding region. These stress changes may increase the stress on favorably oriented faults in the region, leading to the subsequent occurrence of earthquakes on some of them that may be attributed to the triggering effect of the stress increase.

Stress is measured in units of bars, which is roughly atmospheric pressure at sea level. Stress changes as a consequence of CST are often no more than a few bars except in close proximity to a source fault. It is unclear why such small stress changes seemingly cause such large changes in seismic activity, because most earthquakes are caused by static stress drops of 30 bars or more. It is also unclear why there is a delay between the instantaneous increase in stress caused by the first event and the occurrence of the triggered events. The presence of such a delay indicates that other processes, beyond CST, are also involved in the generation of the triggered earthquakes. For example, the delay may be due in part to viscoelastic effects (e.g., $[18,19])$. CST calculations assuming static, purely elastic models may not accurately estimate longer term effects because viscoelastic effects may play an importance role in earthquake triggering. Potential alternative causes of the delay include rate and state friction, stress corrosion, fluid migration, after slip, and poroelastic effects [20].

Most studies of CST are retrospective, examining whether past earthquakes occurred as a consequence of CST, and are used to test the accuracy of CST forecasts. Of more interest to us is whether prospective CST can be used to indicate the current state of stress, and to use this to forecast locations where future earthquakes are more likely to occur as a consequence of the occurrence of the first event. Such prospective studies could potentially estimate how much closer to rupture a fault has been brought. Several different strategies have been suggested for converting a change in stress to a change in probability of an earthquake [21-23]. Accurate earthquake forecasting based on CST is thus contingent on the availability of accurate stress change estimates as well as on realistic methods for relating them to changes in earthquake probabilities. This needs to be borne in mind as we next review the use of measured postTohoku stress changes to make quantitative estimates of changes in seismicity.

\section{Estimates of post - Tohoku changes in seismicity rate in} the Southern Kanto Region based on CST

Numerous research papers have reported abrupt changes in seismicity rate and distributions of focal mechanism solutions following the 2011 Tohoku earthquake, including Hiratsuka and Sato [24], Hirose et al. [1]; Asano et al. [25]; Kato et al. [26]; Kumazawa and Ogata [27] and Yoshida et al [28]. Several studies have tested whether selected aftershocks were triggered by CST. For example, Toda et al. [29] found retrospectively that 5 of the 7 largest aftershocks were triggered by CST, being brought closer to failure by $\geq 0.3$ bars. Using the same tests, they found prospectively that large sections of the Japan Trench, the outer trench slope faults, the Kanto fragment beneath Tokyo and the Itoigawa-Shizuoka Tectonic Line (ISTL) were also brought $\geq 0.3$ bars closer to failure (red regions in Figure 5). Sato et al. [30] carried out similar tests, using a different initial model, on 81 aftershocks occurring within 25 days of the Tohoku mainshock. They reported that $85 \%$ of these aftershocks were found to be positively stressed, also consistent with the CST hypothesis.

Similarly, Ishibe et al. [31] found that the increase in seismicity in the Kanto region after the 2011 Tohoku earthquake could be retrospectively forecast on the basis of calculation of static changes in the Coulomb Failure Function (CFF) in over 30,000 small earthquakes. Almost 19,000 previous events in this region indicated a significant increase in CFF compared with less than 6,000 that indicated a significant decrease. However, they found that the increase in predicted seismicity is concentrated in four 
regions, shown in Figure 7. Two of these regions are in the shallow crustal areas of the Izu and Hakone volcanic regions, and present low seismic hazard to Tokyo. The other two of these regions are deeper and lie in southwestern Ibaraki and northern Chiba prefectures. The northern Chiba and southwestern Ibaraki regions, which are closest to Tokyo, have long been identified by historical seismicity as an active region near Tokyo. In the plate geometry model of Uchida et al. [11], these earthquakes are occurring in the vicinity of the interface between the Philippine Sea plate and the Okhotsk plate in the depth range of 30 to $50 \mathrm{~km}$ (top left of Figure 4). In the plate geometry model of Toda et al. [7], they are associated with the hypothesized Kanto Fragment (bottom left of Figure 4, at whose base a postTohoku increase in stress was calculated by CST, Figure 5) and the Kanto Corridor (discussed next).

Post-Tohoku earthquake probabilities in the Kanto corridor Toda and Stein [32] observed a ten-fold increase in seismicity rate in the Kanto Corridor (Figure 8), which includes parts of regions $\mathrm{C}$ and D in Figure 7, immediately following the Tohoku earthquake, and a decrease to a new rate after one year that was still three times the pre-Tohoku rate.

Toda and Stein [32] found that these seismicity observations can be explained by CST, and used CST to estimate the time-dependent probability of large earthquakes in the Kanto region beneath Tokyo. The largest post-Tohoku events in the Kanto Corridor have had magnitudes of Mjma of 6.0, so their forecast earthquake probabilities of larger earthquakes that are the focus of our interest is based on extrapolation, but appears to be justified by the observation that the Gutenberg-Richter " $b$ " value (measuring relative numbers of small and large events) has not changed since the Tohoku earthquake. Their calculations produce probabilities of $43 \%$ and $17 \%$ of earthquakes occurring beneath Tokyo with magnitudes greater than 6.5 and 7.0 respectively in the time period 11 March 2013 to 10 March 2018. These values are about 2.5 times the probabilities had the Tohoku earthquake not occurred. The equivalent one year probabilities are $10 \%$ and $4 \%$ respectively.

Ozawa et al. [33] used onshore GPS data to identify a region of large (1.0 to $1.9 \mathrm{~m}$ ) aseismic slip off the Boso Peninsula, shown in Figure 9. Uchida and Matsuzawa [14] estimated about $0.5 \mathrm{~m}$ of aseismic slip off Choshi on the Boso Peninsula (southernmost orange patch in the upper right panel of Figure 10) from small repeating earthquakes. Toda and Stein [32] infer that these aseismic slips increased the stressing rate on the thrust faults to the west beneath southern Kanto. However, Toda and Stein [32] note that there are counter-arguments to their estimate of an increased earthquake probability: that the post-Tohoku seismicity in the Kanto region could simply be accompanying accelerated creep on uncoupled thrust faults beneath Kanto.

Uchida and Matsuzawa [14] inferred fault slip on the Japan trench subduction zone and in the Kanto region from repeating earthquakes, estimating a $3 \mathrm{~cm} / \mathrm{yr}$ slip rate in the Kanto region during 1993-2010, and $32 \mathrm{~cm}$ of slip from 11 March - 31 December 2011, or about 10 times the preTohoku rate, as shown in Figure 10. This implies that slip beneath Kanto could be fully uncoupled, in which case the accelerated post-Tohoku slip on Kanto faults could be reducing, not increasing, the stress imparted by the Tohoku earthquake. This is consistent with the interpretation of geodetic data by Nishimura et al. [4], who found that with the exception of the site of the $1938 \mathrm{Mw} 7.3,7.4,7.5$ earthquake swarm, which since ruptured in the 2011 Tohoku earthquake, the Pacific -Okhotsk subduction zone east of Tokyo including the Off Boso segment has low seismic potential, although GPS data in the far offshore region are

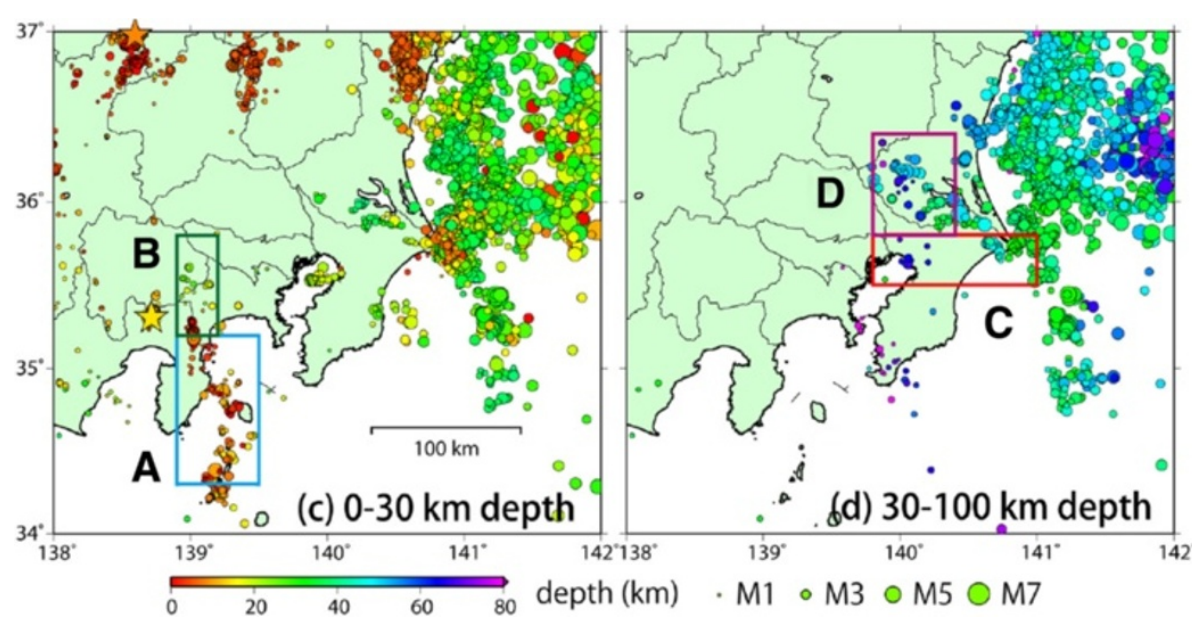

Figure 7 Regions near Tokyo retrospectively forecast as having high increased seismicity by CST. Left panel: shallow earthquakes in the IzU (A) and Hakone (B) volcanic regions. Right panel: deep earthquakes in northern Chiba (C) and southwestern Ibaraki (D). Source: Ishibe et al. [31]. 

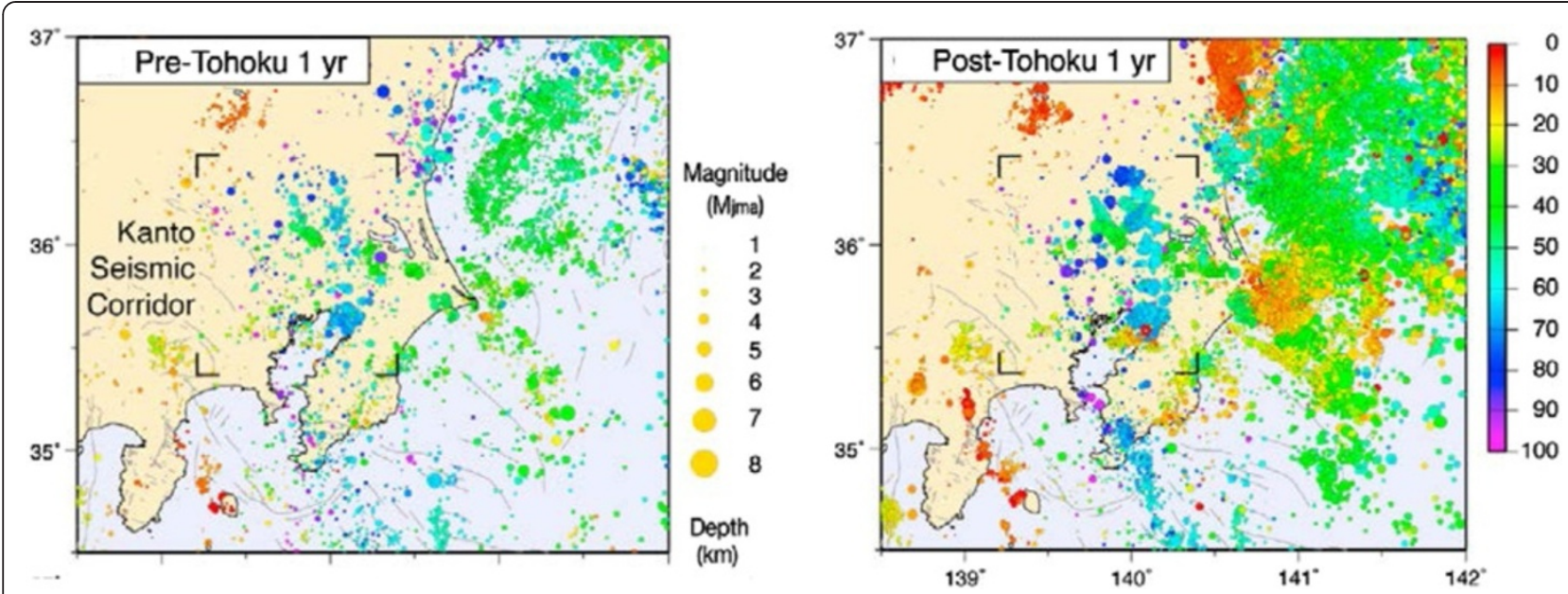

Figure 8 One year of seismicity in the southern Kanto region before (left) and after (right) the 2011 Tohoku earthquake. The Kanto Corridor is indicated by brackets. Source: Toda and Stein [32].

needed to confirm this conclusion. Therefore, although Figure 5 indicates a large stress transfer to the Off Boso segment as a result of the 2011 Tohoku earthquake, Figure 3 suggests the possibility that some of this stress is being released aseismically in creep. The analysis of Uchida and Matsuzawa [14] and Loveless and Meade [34] does not preclude the occurrence of future seismic slip in earthquakes on those creeping fault patches shown in Figure 10 that are distant from the Tohoku rupture zone. Indeed, several magnitude $>6$ Tohoku aftershocks occurred in the off Boso region, indicating that the interface there may not be completely decoupled.

Not all studies suggest that CST is responsible for the seismic activity post Tohoku. Miyazawa [35] found that early events triggered by the $2011 \mathrm{Mw} 9.0$ Tohoku earthquake systematically propagated over Japan in a southwestern direction, associated with the strong seismic waves from the source. The propagation front was consistent with the arrivals of large amplitude surface waves traveling at 3.1 to $3.3 \mathrm{~km} / \mathrm{s}$ and extending to a distance of 1,350 km. Miyazawa [35] claims that there were no observations of triggered earthquakes in the northern direction, but dynamic stress changes toward the north were comparable to or smaller than those necessary for triggering in the southwestern direction. He further notes that static stress changes were one to two orders of magnitude smaller than dynamic stress changes at remote distance, suggesting that static stress was not the main mechanism of the triggering.

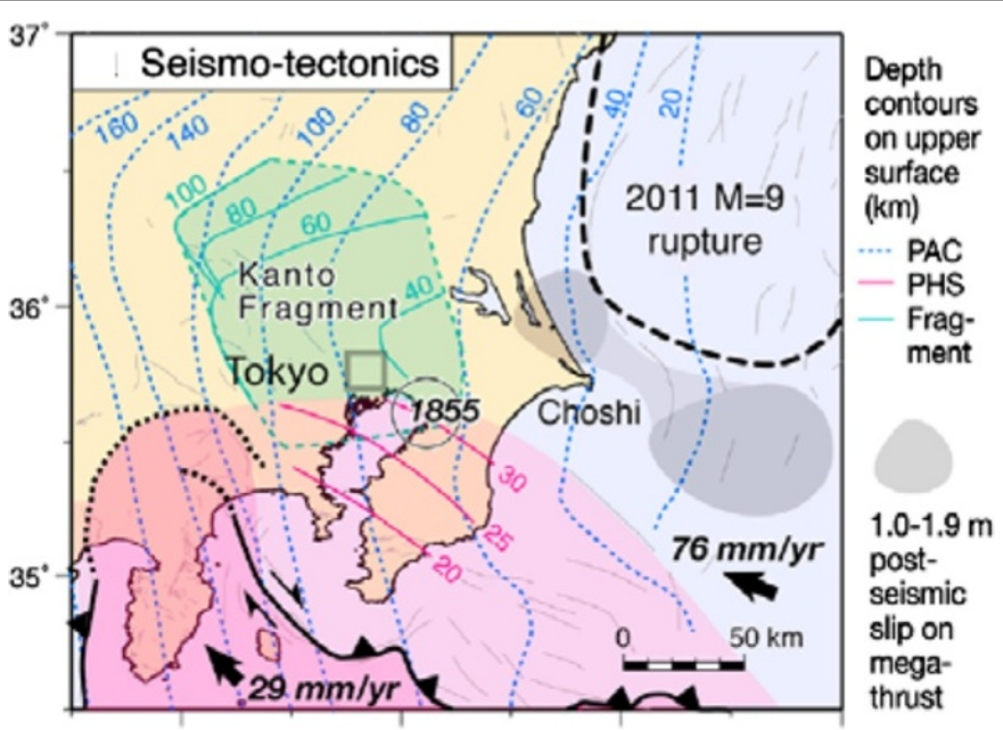

Figure 9 Region of post-Tohoku slip on the plate interface in the Off Boso region determined by Ozawa et al. [33], shown by the shaded grey area south of the $2011 \mathrm{M}=9$ rupture zone. Source: Toda and Stein [32]. 


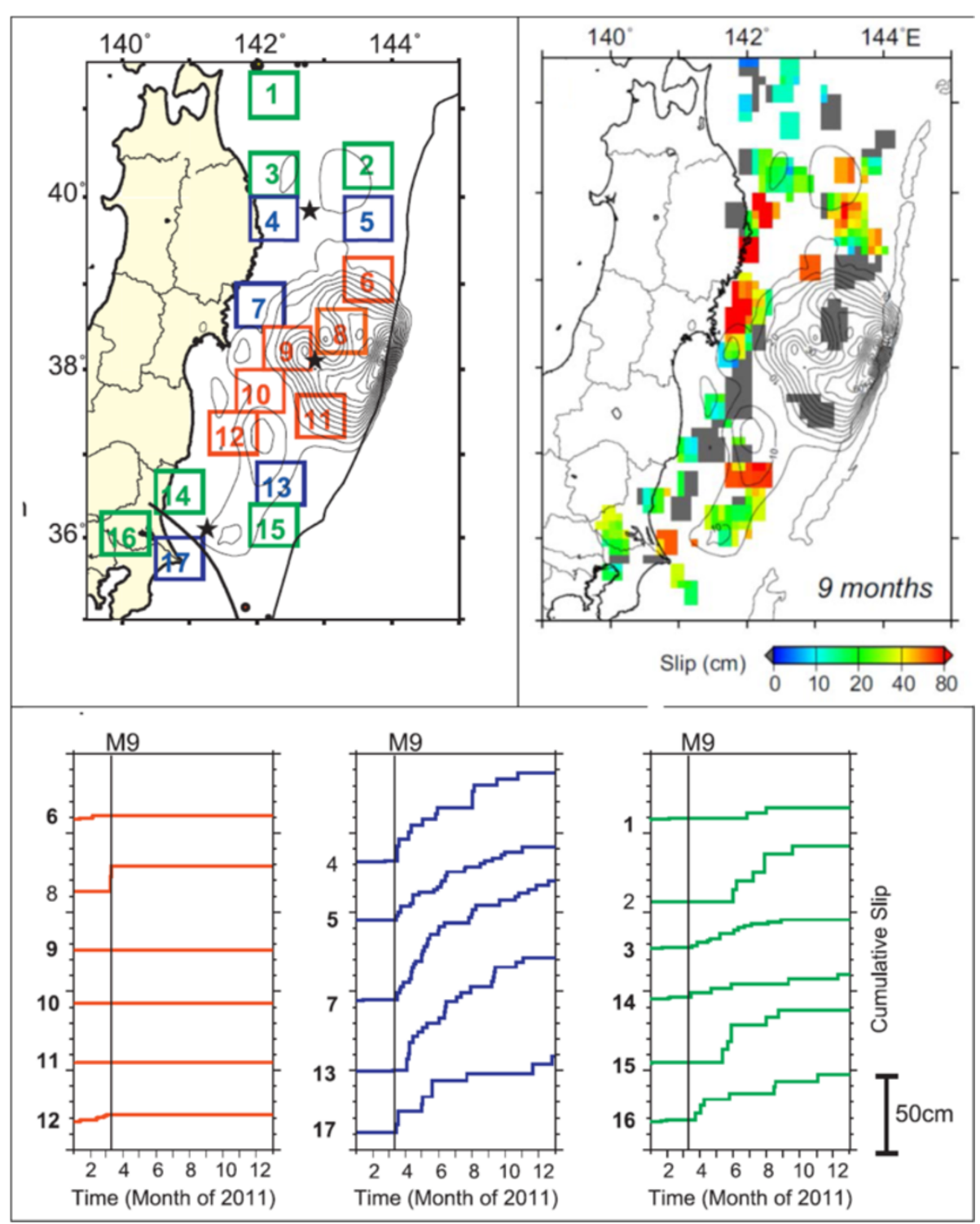

Figure 10 Lower panels show aseismic slip (creep) following the Tohoku earthquake in various regions shown in the top left panel. The top right panel shows the total creep that occurred in the 9 months following the Tohoku earthquake based on repeating small earthquakes. There has been little post-Tohoku creep on the plate interface within the rupture zone of the Tohoku earthquake (shown in red), but significant post-Tohoku creep on the adjoining regions to the north and south (shown in blue and green). Source: Uchida and Matsuzawa [14].

Delayed events could also be a consequence of dynamic rather than static stress triggering.

\section{Post Tohoku earthquake probabilities in the Southern Kanto District}

Nanjo et al. [36] estimated post-Tohoku time-dependent earthquake probabilities for a region of southern Kanto $\left(35.0-36.5^{\circ} \mathrm{N}, 139.3-140.8^{\circ} \mathrm{E}, \mathrm{M}>1.0\right)$ that is larger than the Kanto Corridor considered by Toda and Stein [32]. They used the earthquake catalogue up to May 30, 2012 and standard laws of earthquake statistics: the Gutenberg-Richter frequency-magnitude law and the
Omori-Utsu aftershock-decay law. Their earthquake probability estimates are higher than pre-earthquake levels if a period of 3-yr duration or shorter is considered. However, taking into account the contribution of errors that arise from parameter estimation in the probability calculations, they conclude that any increase in the probability of earthquakes is insignificant. They calculate the current probability of occurrence of one or more earthquakes in the magnitude range of 6.7-7.2 in the southern Kanto district during any 30 -yr period to be 70 per cent, the same as before the Tohoku earthquake. This indicates that the Post-Tohoku increase in seismicity is concentrated in the 
Kanto Corridor and is not present in the broader southern Kanto region.

\section{Conclusions}

Consideration of the information reviewed above gives rise to the following conclusions about the likelihood of future damaging earthquakes in Tokyo.

\section{Repeat of the $1923 \mathrm{Mw}$ 8.0 Kanto earthquake}

The 2011 Tohoku earthquake is thought to have reduced the stress on the region of the interface between the Philippine Sea plate and the Okhotsk plate on which the 1923 earthquake occurred (Figure 5), and so this region of that plate interface is not currently a focus of major concern regarding future earthquakes in Tokyo. There appears to be no controversy concerning this conclusion.

\section{Deeper earthquakes beneath Tokyo}

Uchida et al. [11] conclude that coincidence of the northeastern limit of the Philippine Sea plate estimated from focal mechanisms with the edge of the wedge shape of the plate derived from converted wave data supports the prevailing view that the Philippine Sea plate the extends well north of the northern margin of Tokyo Bay, and is inconsistent with the Kanto Fragment hypothesis of Toda et al. [7], which attributes deep earthquakes in this region to a broken fragment of the Pacific plate. Toda and Stein [32] conclude that the high level of seismicity in the Kanto Corridor is related to their hypothesized Kanto Fragment.

Toda and Stein [32] conclude that CST has increased the stress on faults in the southern Kanto district, and that the probability of earthquakes on such faults within the Kanto Corridor has increased by a factor of 2.5 for the time period 11 March 2013 to 10 March 2018. Estimates of earthquake probabilities by Nanjo et al. [36] based on post-Tohoku observed seismicity in a larger region of the Southern Kanto District using standard statistical laws indicate no significant increase in the probability of earthquakes in this larger region. The results of Uchida and Matsuzawa [14] (Figure 10) suggest the possibility, recognized by Toda and Stein [32], that fault creep in southern Kanto may be slowly relaxing the stress increase caused by the Tohoku earthquake that might otherwise cause more large earthquakes, although GPS measurements indicating such creep have not been made.

\section{Large earthquake on the Off boso segment}

Stress transfer calculations (Figure 5) indicate a large stress transfer to the Off Boso Segment as a result of the 2011 Tohoku earthquake. However, Ozawa et al. [33] used onshore GPS measurements to infer large postTohoku creep on the plate interface in the Off-Boso region (Figure 9), and Uchida and Matsuzawa [14] measured similar large creep off the Boso Peninsula (Figure 10). This is consistent with the interpretation of geodetic data by Nishimura et al. [4], who find that the Pacific-Okhotsk subduction zone east of Tokyo including the Off Boso segment may have low seismic potential (Figure 3), although GPS data in the far offshore region are needed to confirm this conclusion. Therefore, although Figure 5 indicates a large stress transfer to the Off Boso Segment as a result of the 2011 Tohoku earthquake, Figures 9 and 10 suggest the possibility that this stress is being released aseismically, consistent with the pre-Tohoku geodetic data shown in Figure 3, leading to the possibility that a large earthquake on this segment has a low probability. The site of the $1938 \mathrm{Mw} 7$ earthquake swarm shown in Figure 3 is thought to have ruptured in the 2011 Tohoku earthquake, and to have low current potential to produce large earthquakes.

\section{Abbreviations}

CST: Coulomb stress transfer; GPS: Global positioning system.

\section{Competing interests}

Guy Carpenter \& Company, a reinsurance broker, has provided sponsorship fees to Risk Frontiers for the past two decades for the purpose of improving the scientific understanding of natural hazards in Australasia, and funded the preparation and publication of this review article. The author does not hold any stocks or shares in an organization that may in any way gain or lose financially from the publication of this manuscript, either now or in the future. The author does not hold and is not currently applying for any patents relating to the content of the manuscript, and has not received reimbursements, fees, funding, or salary from an organization that holds or has applied for patents relating to the content of the manuscript. The author does not have any other financial competing interests.

\section{Authors' information}

Dr Paul Somerville is Chief Geoscientist and Adjunct Professor at Risk Frontiers, Macquarie University, Sydney, Australia; is President of the Australian Earthquake Engineering Society; and is Principal Seismologist at URS Corporation, LoS Angeles, USA. He was a visiting Research Fellow at the Earthquake Research Institute, University of Tokyo, from 1977 to 1979

\section{Acknowledgments}

The author is grateful for the insights provided by Dr Naoshi Hirata, Dr Takeo Ishibe, and Dr David Okaya during a visit to the Earthquake Research Institute, University of Tokyo. Guy Carpenter \& Company funded the preparation and publication of this review article.

Received: 10 January 2014 Accepted: 21 April 2014

Published: 21 July 2014

\section{References}

1. Hirose FK, Miyaoka N, Hayashimoto Yamazaki T, Nakamura M (2011) Outline of the 2011 off the Pacific coast of Tohoku Earthquake (Mw 9.0) -Seismicity: foreshocks, mainshock, aftershocks, and induced activity. Earth Planets Space 63(7):513-518

2. Wald DJ, Somerville PG (1995) Variable-slip rupture model of the great 1923 Kanto, Japan, earthquake: geodetic and body-waveform analysis. Bull Seismol Soc Am 85(1):159-177

3. Stein R, Toda S, Parsons T, Grunewald E (2006) A new probabilistic seismic hazard assessment for greater Tokyo. Phil Trans R Soc A. doi:10.1098/rsta.2006.1808

4. Nishimura T, Sagiya T, Stein RS (2007) Crustal block kinematics and seismic potential of the northernmost Philippine Sea late and Izu microplate, central Japan, inferred from GPS and leveling data. J Geophys Res 112: doi:10.1029/ 2005JB004102

5. Ishibashi K (2004) Status of historical seismology in Japan. Ann Geophys 47 (2/3):339-368 
6. Somerville PG (1980) Earthquake mechanisms at the head of the Philippine Sea plate beneath the southern Kanto District, Japan. J Phys Earth 28:293-308

7. Toda S, Stein RS, Kirby SH, Bozkurt SB (2008) A slab fragment wedged under Tokyo and its tectonic and seismic implications. Nat Geosci 1:1-6, doi:10.1038/ngeo1318

8. Sekiguchi H, Yasumi M, Horikawa H (2011) Broadband Ground Motion Simulation for Great Interplate Earthquakes With Multi-Scale Heterogeneous Source Modeling. Proceedings of the 4th IASPEI/IAEE International Symposium: Effects of Surface Geology on Seismic Motion, August 23-26, 2011. University of California Santa Barbara, http://esg4.eri.ucsb.edu/

9. Ishida M (1992) Geometry and relative motion of the Philippine Sea plate and Pacific plate beneath the Kanto-Tokai district, Japan. J Geophys Res 97:489-513

10. Ishida M (1995) The seismically quiescent boundary between the Philippine Sea plate and the Eurasian plate in central Japan. Tectonophysics 243:241-253

11. Uchida N, Matsuzawa T, Nakajima J, Hasegawa A (2010) Subduction of a wedge-shaped Philippine Sea plate beneath Kanto, central Japan, estimated from converted waves and small repeating earthquakes. J Geophysical Res 115:B07309, doi:10.1029/2009JB006962

12. Noguchi S (1998) Seismicity, focal mechanisms and location of volcanic front associated with the subducting Philippine Sea and Pacific plates beneath the Kanto district, Japan, Bull. Earthquake Res Inst Univ Tokyo 73:73-101, in Japanese, with English abstract

13. Toda S, Lin J, Stein RS (2011b) Using the $2011 \mathrm{M}=9.0$ Tohoku earthquake to test the Coulomb stress triggering hypothesis and to calculate faults brought closer to failure. Earth Planets Space 63:1-6, doi:10.5047/eps.2011.05.010

14. Uchida N, Matsuzawa T (2013) Pre- and post-seismic slow slip surrounding the 2011 Tohoku-Oki earthquake rupture. Earth Planet Sci Lett 374(81-91):2013, doi: 10.1016/j.epsl.2013.05.021

15. Earthquake Research Committee (2004) Evaluations of occurrence potentials for subduction-zone earthquakes to date (in Japanese). http://www.jishin.go. jp/main/chousa/04aug_sagami/sagami.pdf

16. Stein $R$ (1999) The role of stress transfer in earthquake occurrence. Nature 402:605-609, doi:10.1038/45144

17. Kumagai $H$ (1996) Time sequence and the recurrence models for large earthquakes along the Nankai Trough revisited. Geophys Res Lett 23(10):1139-1142

18. Pollitz FF (1996) Coseismic deformation from earthquake faulting on a layered spherical Earth. Geophys J Int 125:1-14

19. Freed AM, Lin J (1998) Time-dependent changes in failure stress following thrust earthquakes. J Geophys Res 103(24):393-24,409

20. Freed AM (2005) Earthquake triggering by static, dynamic, and postseismic stress transfer. Annu Rev Earth Planet Sci 33:335-367, doi: 10.1146/annurev earth.33.092203.122505

21. Dieterich J (1994) A constitutive law for rate of earthquake production and its application to earthquake clustering. J Geophys Res 99:2601-2618

22. Stein R, Barka A, Dieterich J (1997) Progressive failure on the North Anatolian fault since 1939 by earthquake stress triggering. Geophys J Int 128:594-604

23. Hardebeck J (2004) Stress triggering and earthquake probability estimates. J Geophys Res 109:B04310, doi:10.1029/2003JB002437

24. Hiratsuka S, Sato T (2011) Alteration of stress field brought about by the occurrence of the 2011 off the Pacific coast of Tohoku earthquake (Mw 9.0). Earth Planets Space 63:681-685

25. Asano $Y$, Saito T, Ito $Y$, Shiomi K, Hirose H, Matsumoto T, Aoi S, Hori S, Sekiguchi S (2011) Spatial distribution and focal mechanisms of aftershocks of the 2011 off the Pacific coast of Tohoku Earthquake. Earth Planets Space 63(7):669-673

26. Kato A, Sakai S, Obara K (2011) A normal-faulting seismic sequence triggered by the 2011 off the Pacific coast of Tohoku Earthquake: Wholesale stress regime changes in the upper plate. Earth Planets Space 63(7):745-748

27. Kumazawa T, Ogata Y (2013) Quantitative description of induced seismic activity before and after the 2011 Tohoku-Oki Earthquake by non-stationary ETAS models. J Geophys Res-SOLID 118:6165-6182, doi:10.1002/2013JB010259

28. Yoshida K, Hasegawa A, Okada T, linuma T, Ito Y, Asano Y (2012) Stress before and after the 2011 great Tohoku-oki earthquake and induced earthquakes in inland areas of eastern Japan. Geophys Res Lett 39:L03302, doi:10.1029/2011GL049729

29. Toda S, Stein RS, Lin J (2011a) Widespread seismicity excitation throughout central Japan following the $2011 \mathrm{M}=9.0$ Tohoku earthquake, and its interpretation by Coulomb stress transfer. Geophys Res Lett 38:L00G03, doi:10.1029/2011GL047834
30. Sato T, Hiratsuka S, Mori J (2012) Coulomb stress change for the normal-fault aftershocks triggered near the Japan Trench by the $2011 \mathrm{MW}$ 9.0 Tohoku-Oki earthquake. Earth Planets Space 64:1239-1243

31. Ishibe T, Shimazaki K, Satake K, Tsuruoka H (2011) Change in seismicity beneath the Tokyo metropolitan area due to the 2011 off the Pacific coast of Tohoku Earthquake. Earth Planets Space 63(7):731-735

32. Toda S, Stein R (2013) The 2011 M=9.0 Tohoku oki earthquake more than doubled the probability of large shocks beneath Tokyo. Geophys Res Lett 40:, doi:10.1002/grl.50524

33. Ozawa S, Nishimura T, Munekane $H$, Suito $H$, Kobayashi T, Tobita M, Imakiire T (2012) Preceding, coseismic, and postseismic slips of the 2011 Tohoku earthquake, Japan. J Geophys Res 117:B07404, doi:10.1029/2011JB009120

34. Loveless JP, Meade BJ (2011) Spatial correlation of interseismic coupling and coseismic rupture extent of the $2011 \mathrm{Mw}=9.0$ Tohoku-oki earthquake. Geophys Res Lett 38:L17306, doi:10.1029/2011GL048561

35. Miyazawa M (2011) Propagation of an earthquake triggering front from the 2011 Tohoku-Oki earthquake. Geophys Res Lett 38:L23307, doi:10.1029/ 2011GL049795

36. Nanjo KZ, Sakai S, Kato A, Tsuruoka H, Hirata N (2013) Time-dependent earthquake probability calculations for southern Kanto after the 2011M9.0 Tohoku earthquake. Geophys J Int, doi: 10.1093/gji/ggt009

doi:10.1186/2196-4092-1-10

Cite this article as: Somerville: A post-Tohoku earthquake review of earthquake probabilities in the Southern Kanto District, Japan. Geoscience Letters 2014 1:10.

\section{Submit your manuscript to a SpringerOpen ${ }^{\circ}$ journal and benefit from:}

- Convenient online submission

- Rigorous peer review

- Immediate publication on acceptance

- Open access: articles freely available online

- High visibility within the field

- Retaining the copyright to your article

Submit your next manuscript at $>$ springeropen.com 